\title{
Rosa Luxemburgo e o Mundo Subdesenvolvido ${ }^{1}$
}

Armando Córdova ${ }^{2}$

\section{Apresentação}

A acumulação de capital de Rosa Luxemburgo abrange num só objeto de análise tanto o capitalismo maduro dos países desenvolvidos, como as formas "não capitalistas" penetradas pela expansão do capital na Ásia, África, América e Oceania, onde surgiram como resultado da dominação burguesa "as mais estranhas formas mistas entre o moderno sistema de salário e os regimes primitivos" (Luxemburgo, 1967, p.279). Nesta obra se misturam, portanto, os elementos explicativos tanto do desenvolvimento histórico do capitalismo nos centros dominantes, como do processo de formação e evolução do que hoje se denominam países subdesenvolvidos.

A quase totalidade dos comentários e críticas que tal obra suscitaram desde o próprio momento de sua aparição em 1912 foram feitas considerando unicamente sua visão da problemática das sociedades capitalistas centrais a partir das quais sua autora escreveu, visão que com frequência tem sido deformada e limitada pelas implicações que a análise teve sobre o os julgamento de fatos e situações concretas vividas por ela ou por seus críticos ${ }^{3}$.

\footnotetext{
${ }^{1}$ Tradução do original em castelhano por Tomás de Siervi Barcellos, mestrando do Programa de Pós-Graduação em Ciências Sociais - Estudos Comparados sobre as Américas da Universidade de Brasília (PPGECsA-UnB) e Raphael Lana Seabra, professor adjunto no mesmo programa (PPGECsA-UnB). O presente artigo foi publicado originalmente em Problemas del Desarrollo. Revista Latinoamericana de Economía, volume 5, número 18, 1974.

${ }^{2}$ Economista venezuelano falecido em 2011. Doutor em Ciências Econômicas e Sociais pela Universidade Central da Venezuela (UVC) foi professor titular da UCV, professor visitante das Universidades de Bielefeld e Münster na Alemanha e do Instituto para Estudo da Sociedade Contemporânea na Itália. Doutor Honoris Causa pela Universidade Simón Bolívar de Barranquila, Colômbia. Sua principal obra, redigida em conjunto com Héctor Silva Michelena, foi Aspectos Teóricos del Subdesarrollo.

${ }^{3}$ Desde sua aparição A acumulação de capital foi objeto de uma crítica ([Eduard] Berstein, [Otto] Bauer, [Karl] Kautsky) prejudicada pelas diferenças de caráter tático e estratégico existentes entre tais autores e Rosa Luxemburgo. Mesmo a crítica de Lenin não escapou a certo pré-condicionamento de seu julgamento pelos desacordos com a autora. A respeito de comentaristas posteriores, desde a década de 1920 até o presente, Lenin já chamava a atenção em 1922 ("Notas de um publicista", Obras Completas, tomo 33) sobre as manobras (Levy) de reeditar de maneira "selecionada" algumas das obras de Rosa Luxemburgo com a intenção de colocá-las ao serviço de interesses contrários à revolução, do mesmo modo comentam dois autores contemporâneos as intenções de "reabilitação" de Rosa Luxemburgo para pô-la à serviço de posições teóricas e políticas que não têm nada a ver com suas ideias e nem toma em conta nada sobre as diferenças de contexto histórico (Bensaid, Nair, 1969).
}

Revista de Estudos e Pesquisas sobre as Américas V.13 N.1 2019 ISSN: 1984-1639 
O objeto deste trabalho é buscar uma visão desta obra desde a perspectiva dos países subdesenvolvidos, esse outro extremo de seu modelo do sistema capitalista mundial que sua autora indicou como imprescindível complemento do desenvolvimento capitalista dos centros hegemônicos. Não pretendo que esta visão seja suficiente e absoluta para julgar sua obra, igualmente que não é também a visão marcadamente eurocêntrica, e por fim parcial, da grande maioria de seus críticos e comentaristas. Acredito sim, que nosso enfoque é, tal como o outro, um passo necessário do processo de análise, um momento da reflexão crítica sobre a obra, antes de passar à visão global que possa nos levar à síntese de sua totalidade, que não é outra coisa que a síntese do sistema capitalista mundial visto como totalidade histórica que continha em seu desenvolvimento tanto um polo capitalista desenvolvido como um polo atrasado e dependente, ambos unidos por um sistema de relações que fazia de cada polo um aspecto imprescindível para explicar o outro.

O plano de trabalho que me propus é o seguinte: em primeiro lugar estudarei os antecedentes dentro do marxismo em relação à questão dos países atrasados. Em tal sentido, apresento uma breve síntese do que considero a visão de Marx e Engels sobre isso e, em seguida, algumas ideias que tinham os contemporâneos de Rosa Luxemburgo localizados na II Internacional sobre tal problema. Em segundo lugar, passo a expor as ideias da autora relacionando-as com distintas concepções teóricas que se tiveram até agora sobre o tema do subdesenvolvimento. Finalmente, busco fazer algumas considerações sobre as críticas a $A$ acumulação do capital que considero relacionadas, de uma forma ou de outra, com os critérios que aqui sustento.

O leitor perceberá que não faço aqui suficientes referências ao que se poderia considerar como abordagem leninista sobre a questão; isso se deve ao que espero desenvolver o tema num ensaio a parte.

\section{A Visão de Marx e Engels}

Como aponta Georg Lukács, o que distingue o marxismo de maneira decisiva da ciência burguesa é o ponto de vista da totalidade (Lukács, 1960). De fato, a obra de Marx parte de uma visão de mundo de sua época concebido com um todo complexo em constante processo de mudança e formação, no qual já "reinava um intercâmbio universal e uma interdependência universal das nações” (Marx, Engels, 1973, p. 4). O pensamento marxista se 
desenvolve, precisamente, em busca das leis objetivas capazes de explicar o funcionamento e desenvolvimento desse todo heterogêneo e cambiante.

Desde o Manifesto Comunista Marx e Engels estabelecem que o sujeito histórico que havia conseguido romper "o isolamento das regiões e nações que bastavam a si mesmas", até conformar esse todo integrado, era uma classe social, a burguesia, que buscando forjar em todas as partes um mundo a sua imagem e semelhança "arrastou à corrente da civilização todas as nações" (Marx e Engels, 1973, p.4). Daí que o primeiro passo para compreender tal mundo fosse a busca das leis objetivas que regem o comportamento da burguesia e do modo de produção que a alça a classe dominante, em motor da história. Foi essa a tarefa que Marx cumpriu ao escrever $O$ Capital.

O resultado de tal obra foi um modelo teórico abstrato, homogêneo e fechado do modo capitalista de produção. Abstrato porque nele se põe de lado as circunstâncias históricas concretas na busca das relações essenciais do capitalismo ${ }^{4}$. Homogêneo porque supõe uma totalidade integrada unicamente por duas classes sociais, capitalistas e operários ${ }^{5}$. Fechado porque ao abranger com essa totalidade todo o mundo teórico, as relações internacionais eram consideradas como elementos endógenos ao modelo ${ }^{6}$.

Dentro de tal contexto teórico e metodológico ficava, assim, excluído a priori todo o mundo não capitalista, ao que se fazia referência apenas enquanto ponto de partida da gênese do modelo, como fonte da "acumulação originária" do capital ${ }^{7}$. Não é que Marx não tivesse consciência de que o fluxo de excedentes econômicos desde o mundo não capitalista ao capitalista nunca tenha parado, senão que o considerava em seu enfoque como resultado, já das condições particularmente vantajosas em que os países capitalistas realizavam suas transações comerciais com as colônias e outras zonas atrasadas, já da exploração nelas de relações de produção não-capitalistas, as quais aparecem excluídas do modelo essencial ${ }^{8}$,

\footnotetext{
${ }^{4}$ Em suas Teorias da Mais-Valia Marx escreveu: “só temos que considerar aqui as formas pelas quais atravessa o capital em suas diversas etapas de desenvolvimento. Não exporemos, portanto, as circunstâncias reais dentro das quais se realiza o processo de produção efetivo" (Apud Luxemburgo, 1973. P.254).

${ }^{5}$ Cf. O Capital, 1946a, p.350.

6 “Aqui - escreve Marx - fazemos caso omisso do comércio de exportação (...). Para enforcar o objeto de nossa investigação em toda sua pureza, livre de todas as circunstâncias concomitantes que possam borrar temos que enfocar aqui todo o mundo comercial como se fosse uma só nação e admitir que a produção capitalista já se instaurou em todas as partes e se apropriou de todos os ramos industriais sem exceção" (Marx, 1946, p.489).

${ }^{7}$ Cf. Marx, 1946, capítulo XXIV.

${ }^{8}$ Em tal sentido se lê em $O$ Capital: “outro problema - que por sua especificidade fica fora do âmbito nossa de investigação - é este: contribui para a elevação da taxa geral de lucro mais elevadas o capital investido no comércio exterior e principalmente no comércio colonial?” (Marx, 1946b, p.237).
}

Revista de Estudos e Pesquisas sobre as Américas V.13 N.1 2019 ISSN: 1984-1639 
posto que ali o processo de acumulação ampliada é explicado tomando em conta unicamente a extração de mais-valia da classe operária metropolitana ${ }^{9}$.

Fica evidente que deste modelo abstrato, homogêneo e fechado não poderia derivar uma interpretação do que hoje denominamos subdesenvolvimento, assim como tampouco podemos derivá-la das exposições gerais da concepção materialista da história, porque como bem ressaltou ele mesmo, Marx não buscou nunca elaborar uma "teoria histórico filosófica da marcha geral fatalmente imposta a todos os povos, quaisquer que sejam as circunstâncias históricas nas quais se encontram" (Marx, 1970, 351).

Coincido, no entanto, com Lukács quando destaca que o que temos definido aqui como caráter abstrato, homogêneo e fechado no modelo de $O$ Capital:

Não era para Marx senão uma hipótese metodológica, a partir da qual deveria progredir para expor os problemas de modo mais amplo, para apresentar a questão enquanto totalidade da sociedade (Lukács, 1960, p.51-52).

Apresentar a questão enquanto totalidade da sociedade significa incluir nela as classes sociais e camadas não capitalistas que ainda persistiam nas sociedades desenvolvidas, assim como também o mundo colonial e semicolonial, como elementos complementares do mundo capitalista desenvolvido da época. Tal apresentação obriga não só a reconsiderar as condições desse desenvolvimento, como também os efeitos gerados pelo sistema de relações internacionais entre uns e outros sobre as estruturas e comportamento histórico dos países atrasados. Em outras palavras, implica apresentar a questão do sistema capitalista mundial como totalidade integrada por dois polos historicamente inseparáveis.

É conhecido que nem Marx nem Engels chegaram a produzir a obra teórica que superaria a mencionada hipótese metodológica. Acreditamos, no entanto, que tanto em suas obras principais como em diversos trabalhos menores, especialmente seus escritos jornalísticos e cartas, encontram-se importantes referências nas quais se avança no sentido sugerido por Lukács.

O primeiro aspecto a se referir aqui, como em toda análise da obra de Marx e Engels, é que eles estudaram o mundo de sua época não apenas para conhecê-lo, mas para transformálo; e dado que essa transformação progressista tinha como meta final a construção do socialismo, sua visão do presente histórico em que viveram estava obviamente relacionada com a problemática da revolução, o que os levava a considerar com centro de seu interesse aqueles países nos quais o desenvolvimento do capitalismo já havia formado um proletariado

\footnotetext{
${ }^{9}$ Este é um suposto básico dos modelos de reprodução de Marx.
} 
capaz de se colocar, com direito e possibilidades, a tarefa de destruir a ordem burguesa. Por volta de 1848, ano de publicação do Manifesto Comunista, naquele grupo de países entravam apenas Inglaterra e França, ainda que já se anunciasse a entrada precipitada dos Estados Unidos. O resto da Europa continha um segundo conjunto de países nos quais o modo de produção capitalista já havia alcançado certo grau de desenvolvimento, mas ainda dominavam governos reacionários que freavam sua decisiva imposição, dificultando o crescimento do poder econômico e político da burguesia e, portanto, o desenvolvimento do proletariado. Dois grandes impérios, Rússia e Áustria, exerciam o poder da reação anti-burguesa, opondo-se à unificação política dos demais países europeus (em especial, Alemanha e Itália), cuja divisão impedia a consolidação do mercado interno, freando assim as possibilidades plenas do desenvolvimento industrial. Nestes países, o problema fundamental era a solução da "questão nacional" através da aliança entre burguesia e proletariado, para realizar a "revolução democrático-burguesa" como passo prévio à criação das condições objetivas e subjetivas da revolução socialista ${ }^{10}$.

O quadro político da época se completava com o mundo não-capitalista, com o conjunto de países coloniais e semi-coloniais espalhados nos outros quatro continentes. A visão histórica de Marx e Engels sobre estes países tinha de ser bastante complexa e difícil de agarrar. Eles haviam estudado o surgimento do capitalismo na Europa Ocidental "desde as entranhas do regime feudal" quanto que, em sua época, eram testemunhos de um fenômeno cuja análise tinha que apresentar grandes complicações: a penetração, decomposição e subordinação pelo capitalismo de uma ampla variedade de situações, muito diferentes umas das outras, algumas delas dificilmente assimiláveis aos modos de produções experimentados pela Europa Ocidental.

Com efeito, a situação pré-capitalista que antecede à “acumulação originária” europeia pode ser concebida teoricamente como um modelo puro (feudalismo), ou, no máximo, como fase de transição desse modelo a outro (capitalismo) (Cf. Córdova, 1972). As situações "précapitalistas" do século XIX, ao serem penetradas desde fora pelo capitalismo, ao contrário, não só deixavam de ser pré-capitalistas, senão que conformavam realidades sociais heterogêneas. Ainda mais, de uma heterogeneidade distinta em cada caso, devido às grandes diferenças entre as organizações originais penetradas (China, Índia, Irlanda, os países latinoamericanos etc.), assim como a diferente duração e intensidade que cada caso tem contato direto com o capitalismo. Se, portanto, for agregado o baixo nível de conhecimento geral que

${ }^{10}$ Cf. a obra documentada de Boersner, 1957.

Revista de Estudos e Pesquisas sobre as Américas V.13 N.1 2019 ISSN: 1984-1639 
se possuí naquele momento sobre a história passada e presente desses povos, haveria de se concluir que qualquer esforço de teorização ao redor dessa complexa realidade estava fora das possibilidades reais da ciência social da época. O anterior não significa que Marx e Engels não tiveram uma interpretação sobre a natureza desses países atrasados e do papel que jogavam dentro do sistema capitalista mundial, mas que essa visão estava, pelas razões óbvias destacadas, muito distantes de apresentar a clareza e coerência que tinha seu conhecimento científico do mundo capitalista desenvolvido.

Em diversas passagens da obra de ambos encontramos referências ao papel desempenhado pelo descobrimento da América e pela navegação transoceânica no desenvolvimento da burguesia e do capitalismo, assim como a importância crucial que possuíam para a sua época as relações econômicas entre países avançados e atrasados, mas trata-se sempre de afirmações muito genéricas e, de certo modo, condicionadas por sua visão eurocêntrica e sua posição convencida da prioridade histórica do socialismo nos países capitalistas mais desenvolvidos. Seu interesse pelo estudo de alguns casos concretos de países atrasados esteve igualmente condicionado por seu utilitarismo revolucionário, quando "depois do fracasso das revoluções europeias, o teatro mundial das lutas internacionais se muda para Ásia (Marx, Engels, 1973, p.1). Com grande penetração histórica e com grande sentido de totalidade, Marx vê nos acontecimentos provocados pela política colonial das grandes potências na China e na Índia, fenômenos que podiam ter grandes repercussões na Europa, até o ponto de escrever:

Quiçá seja muito estranha e paradoxal a afirmação de que o próximo levante dos povos da Europa (...) possa depender, com maiores possibilidades do que está ocorrendo agora no Império Celestial - a antítese da Europa - que de qualquer outra causa política existente (...) Porém, não é um paradoxo (Marx, Engels, 1973, p.7).

Com o mesmo sentido escreveu mais de uma vez sobre os acontecimentos que ocorriam na Índia ${ }^{11}$ e em outros lugares do mundo colonial e semicolonial ${ }^{12}$, o que sublinha, no campo dos fatos concretos sua visão de um mundo complexo; cuja problemática social

\footnotetext{
${ }^{11}$ Em carta a Engels de 14 de janeiro de 1858, fazendo referência à rebelião indiana contra a Inglaterra que havia iniciado no ano anterior e que custava grandes esforços do exército inglês, Marx escreveu com evidente entusiasmo: com o drain of men and bullion [a drenagem de homens e ouro - Nota dos Tradutores] que deve custar a Inglaterra, a Índia é agora nossa melhor aliada. Ideia idêntica foi expressa em carata a Danielson em 19 de fevereiro de 1881.

12 Veja nesse sentido os artigos de Marx para o New York Daily Tribune sobre a Birmânia e suas comentadas cartas a Engels sobre a questão irlandesa (1886-1887). Por sua parte, Engels escreveu sobre a guerra chinesajaponesa de meados da década dos anos 1890: "a conquista da China pelo capitalismo proporcionará ao mesmo tempo o impulso para a derrubada do capitalismo na Europa e na América do Norte" (Marx, Engels, 1973, p.323).
}

Revista de Estudos e Pesquisas sobre as Américas V.13 N.1 2019 ISSN: 1984-1639 
havia sido integrada de tal maneira que bastava levantar uma alavanca em um ponto da Terra para todos os outros sintam os efeitos.

A visão de Marx e Engels sofreu importantes transformações desde a época da redação do Manifesto Comunista até o fim de seus dias sobre a natureza das transformações que estavam criando o capitalismo nas zonas dependentes. Em sua primeira fase, que abarca os primeiros artigos de Marx para o New York Daily Tribune, seu enfoque parece ter se limitado por certo progressismos simplista que considerava como progressistas quaisquer que fossem os efeitos imediatos sobre os povos subordinados, todo processo de implantação do capitalismo e de destruição das velhas estruturas econômicas nas colônias. Foi partindo de tal critério que Engels saudou “entusiasticamente” em 1847 a ocupação do México pelos Estados Unidos sob o argumento de que o desenvolvimento desse país latino-americano não poderia ser alcançado sem a tutela do capitalismo estadunidense ${ }^{13}$, argumento similar ao que Marx exporia em seus famosos artigos sobre a Índia onde, depois de rejeitar no plano ético a "sujeira" do colonialismo inglês naquele país, justifica como progressista e mesmo como revolucionária a destruição da indústria indiana nativa pela penetração inglesa (Marx, Engels, 1973, p.24-30).

Neste aspecto, no entanto, foram operadas mudanças importantes na visão de ambos os autores. Em primeiro lugar, me refiro a uma nota de rodapé no terceiro tomo de $O$ Capital, onde, seu autor demonstra ter compreendido a natureza ilusória de sua afirmação sobre o caráter progressista da dominação inglesa na Índia. Ali se lê:

Os métodos de exploração da Índia pelos ingleses revelam melhor que a história de nenhum outro
povo toda uma série de experimentos fracassados e realmente tolos (na prática infames). Em
Bengala criaram uma caricatura da grande propriedade inglesa da terra; no sudeste da Índia uma
caricatura da propriedade parcelada; no noroeste, no que deles dependia, converteram a
comunidade econômica indiana baseada na propriedade coletiva da terra numa caricatura de si
mesma (Marx, 1946b, p.322).

Concordo com o Pedro Scaron (1972, p.8-9), quando ele aponta que em tal afirmação Marx se aproxima da atual concepção de capitalismo subdesenvolvido, concebido como "caricatura" do capitalismo maduro dos países dominantes. Mas onde se pode ver com maior nitidez a mudança da visão de Marx em relação aos países subjugados é em sua abordagem da questão irlandesa, a qual dou particular importância por duas razões, a primeira por ter sido a Irlanda o único país dominado que os fundadores do marxismo conheceram e estudaram

\footnotetext{
${ }^{13}$ No artigo "Die Benegungen von 1847" publicado em 23 de janeiro de 1848 na Deutsche Brüsseler Zeitung expressa Engels: Na América presenciamos a conquista do México, o que nos entusiasma (...) É em interesse do próprio desenvolvimento que México estará no futuro sob tutela dos Estados Unidos (1972, p.183).
}

Revista de Estudos e Pesquisas sobre as Américas V.13 N.1 2019 ISSN: 1984-1639 
diretamente, a segunda, porque, salvo as diferenças, a situação desse país naquela época era muito mais parecida ao que hoje denominamos subdesenvolvimento e dependência do que a que prevalecia nos países coloniais ultramarinos. Sobre isso Marx escrevia em 1869:

Durante muito tempo acreditei que seria possível derrotar o regime irlandês pela ascensão da classe operária inglesa. Sempre expressei este ponto de vista no New York Tribune. Mas um estudo mais profundo me convenceu do contrário. A classe operária inglesa nunca fará nada enquanto não se libertar da Irlanda. A alavanca deve se aplicar à Irlanda. Por isso tem tanta importância o problema irlandês para o movimento social em geral (Marx, Engels, 1973, p.309).

A citação anterior sugere o ponto de ruptura com a posição "progressista" das primeiras exposições de Marx e Engels sobre a matéria que discutimos. Por uma parte, o caso irlandês convence Marx definitivamente de que a expansão mundial do capitalismo não levava necessariamente à implantação mecânica do modo de produção burguês em todas as partes. Pelo contrário, ele constata neste como em outros casos como ao país subjugado são negadas as possibilidades de um desenvolvimento capitalista a imagem e semelhança da metrópole. Por outra parte, a citação coloca em evidência que Marx havia entendido - tal qual Engels - que a exploração de outros países estava permitindo à burguesia dos países mais avançados da Europa criar uma aristocracia operária que servira de amortecedor das lutas revolucionárias do proletariado ${ }^{14}$, o que questionava o critério dominante de que os países subjugados só poderiam ser liberados pelo proletariado metropolitano depois que este houvesse realizado sua revolução socialista. Ao contrário, Marx vê agora a revolução socialista na Inglaterra: “a alavanca deve se aplicar à Irlanda”.

Esta nova posição de Marx sobre o problema irlandês, tal qual certos comentários de Engels sobre a situação chinesa de $1894^{15}$, põem em evidência que, tanto um como o outro, deram maior importância nos últimos anos de suas vidas ao que hoje se denomina terceiro mundo, porque viram nesses países importantes "alavancas" para mobilizar os desenvolvimentos revolucionários dos centros capitalistas. Era o ponto de partida para a revisão de sua posição analítica eurocêntrica que, caso contrário, não estavam em condições de superar plenamente.

\footnotetext{
${ }^{14}$ Este critério foi melhor desenvolvido por Engels posteriormente. Em tal sentido, veja-se a carta a Kautsky de 12 de dezembro de 1882 na qual afirma referindo-se à Inglaterra: “Aqui não há partido operário, só existem conservadores e radicais liberais e os operários participam alegremente na festa do monopólio inglês sobre o mercado mundial" (Marx, Engels, 1973, p.318).

${ }^{15}$ Faço referência a uma carta de Engels a Kautsky de 23 de dezembro de 1894, retornando a uma velha ideia de Marx: "Outra vez mais a maravilhosa ironia da história: só falta a China ser conquistada para a produção capitalista e ao assim fazê-lo, em última instância esta torna impossível sua própria existência na metrópole”.
}

Revista de Estudos e Pesquisas sobre as Américas V.13 N.1 2019 ISSN: 1984-1639 


\section{III - Durante o Período da II Internacional}

A Segunda Internacional foi fundada sob o patrocínio de Engels em 1889 e se manteve até 1917. Durante uma primeira fase, que termina com a morte de seu fundador em 1895, se manteve entre seus integrantes certa unidade de critério sustentada pela indiscutível autoridade daquele, mas, a partir de então, abre-se um período turbulento em que se multiplicaram as dissidências teóricas e de toda ordem entre aqueles que se consideravam herdeiros do pensamento dos fundadores do marxismo, divergências que foram se tornando cada vez mais profundas à medida que se operava o conjunto de transformações econômicas, políticas e sociais que trouxe consigo o advento do imperialismo.

Como resultado, os membros da II Internacional se dividem em quatro grupos: os "marxistas ortodoxos", capitaneados originalmente por Kautsky; os "reformistas e revisionistas", entre os quais se destacava Bernstein; os "austro-marxistas" (Otto Bauer) e os bolcheviques russos com Lenin à frente ${ }^{16}$. Os temas de controvérsia entre estes e outros grupos menores ou personalidades não-alinhadas foram muitos: problemas de organização e construção do movimento revolucionário, problemas teóricos e metodológicos na interpretação do pensamentos dos mestres, mas sobretudo, um conjunto de questões de tática e estratégia revolucionária em relação às importantes mudanças ocorridas e que seguiam ocorrendo, tanto no mundo capitalista como totalidade como no próprio seio das distintas sociedades europeias.

De tudo isso nos interessa aqui pontuar, em função dos fins deste ensaio aqueles aspectos relacionados com as diversas concepções sobre os países coloniais, semicoloniais e dependentes que prevaleciam entre os integrantes da II Internacional, além de traçar, mesmo que apenas em suas linhas gerais, um esboço do ambiente ideológico em que estavam se conformando e desenvolvendo os pontos de vista de Rosa Luxemburgo.

O primeiro aspecto a tratar é aquele que se refere às diversas posições sobre o caráter, significado e implicações do que todos coincidiam em denominar imperialismo. Como é sabido, o primeiro intento de análises de tal fenômeno realizado dentro do campo marxista foi a obra de [Rudolf] Hilferding, O Capital Financeiro" ${ }^{17}$, onde o caracterizava como "fase moderna do desenvolvimento do capitalismo", na qual o velho liberalismo econômico era progressivamente substituído pela concorrência monopolista à medida em que era

\footnotetext{
${ }^{16}$ Nesta parte do trabalho utilizamos referências da obra já citada de Boersner (1957).

${ }^{17}$ Veja-se a referência que Lenin faz a tal obra em Imperialismo, fase superior do capitalismo, 1972.
} 
incrementado o poder dos grandes cartéis e trustes dominados pelo capital financeiro, que havia surgido da fusão do capital industrial com o capital bancário e que se veria impelido a buscar taxas de lucros mais elevadas e fontes vitais de matérias primas nas zonas atrasadas do mundo. Dentro desta caracterização, que seria compartilhada plenamente pelo marxismo ortodoxo, o imperialismo aparece, como bem sugere Goldmann, como resultado de uma política do grande capital e não como um fenômeno histórico inevitável, "admitindo a possibilidade ao menos a teórica de um capitalismo não imperialista" (1969, s.p.) para a época, posição que, como viria a ser demonstrada mais adiante, conduziria à conciliação por parte de Kautsky e seus seguidores da social-democracia com a burguesia.

Por outra parte, dentro desta concepção do imperialismo se estudava quase que unicamente com base em suas manifestações no seio dos países capitalistas avançados e através da influência exercida sobre eles pelo novo sistema de relações internacionais característica dessa fase do capitalismo. Os países atrasados, tão implicados no conceito de imperialismo como os próprios países imperialistas, pois sem eles o fenômeno perderia características que são essenciais, aparecem apenas como objetos remotos de sua ação. Não se colocava nenhuma ênfase nas mudanças estruturais de todo tipo que neles estava produzindo sua introdução na fase imperialista do capitalismo. Dessa maneira se marginalizava os povos da Ásia, África e América Latina como sujeitos da história do sistema mundial ao qual haviam sido incorporados, quer dizer, renunciava-se à categoria de totalidade que é essencial ao marxismo como ciência da sociedade.

Com efeito, o imperialismo implica como condição necessária a existência de países capitalistas com avançado nível de desenvolvimento das forças produtivas e da concentração de capital, nos quais a necessidade de alimentar incessantemente o processo de crescimento acumulativo do capital impõe a expansão para zonas de menor desenvolvimento, para onde exportar capitais excedentes e mercadorias industriais, a partir de onde obter as matérias primas e outros produtos primários requeridos por seu aparato produtivo. Se isso é assim, tanto o primeiro tipo de país como o segundo, conformam aspectos inseparáveis do fenômeno imperialista. Em outras palavras, estamos frente a dois subconjuntos de países que se integram dentro de uma totalidade histórica e estruturada, o sistema capitalista mundial que os contêm. Por consequência, qualquer teoria do imperialismo deve ser capaz de explicar o papel de ambos os polos e as implicações do fenômeno em cada um deles como fator transformador de suas estruturas interiores. A visão do imperialismo de Hilferding e seus seguidores à época é, assim, unipolar, a qual tem sua explicação não só em razões de utilitarismo revolucionário ("a

Revista de Estudos e Pesquisas sobre as Américas V.13 N.1 2019 ISSN: 1984-1639 
revolução só pode ser realizada agora nos países mais avançados”) como também no desconhecimento da situação real do mundo colonial, semicolonial e dependente. Para colocar em evidência tais limitações vale a pena uma referência superficial às discussões sobre "a questão colonial" tiveram lugar no Congresso da II Internacional levada à cabo em Sttutgart em 1907 (Cf. Boersner, 1957).

Foram levantadas ali duas posições opostas, cada uma das quais atribuía a si a correta interpretação do pensamento de Marx. A primeira, sustentada por Van Kol e apoiada por Bernstein, baseava-se nos critérios expressos por Marx e Engels entre 1847 e 1853 com relação à Índia, México e China às quais já nos referimos, para considerar o colonialismo como uma necessidade histórica que cumpriria o objetivo de implantar o capitalismo nas colônias, assentando ali as bases do surgimento e desenvolvimento do proletariado. Seria irresponsável, diziam, abandonar os nativos no estado de barbárie e selvageria do qual só o colonialismo os poderia retirar; em consequência, o colonialismo em si não poderia ser condenado, mas sim as formas impiedosas que utilizava. Os defensores desta tese concluíam pressagiando o advento da revolução proletária para que esta promovera um novo tipo de colonialismo com efeitos civilizadores. A segunda posição, sustentada por Kautsky e Lebedou, ao contrário, destacava que o objetivo do socialismo era liberar as maiorias exploradas de todo o mundo das correntes do capital. Daí que o colonialismo era a antítese da revolução, pois, não só explorava os povos estrangeiros, como apresentava a civilização a tais povos como algo repressivo, ao impô-la pela força bruta. Depois da revolução socialista, os povos atrasados deveriam ser conduzidos à civilização, não através da opressão colonial, mas mediante a ajuda fraterna dos trabalhadores europeus (Cf. Boersner, 1957).

Pode observar-se em ambas as exposições a reafirmação da visão eurocêntrica que os fundadores do marxismo vinham superando em seus últimos escritos, assim com a falta de conhecimento da diversidade de culturas e situações que se apresentavam nas distintas colônias.

Mas, sobretudo, fica absolutamente claro o papel, nem sequer secundário, senão muito mais passivo, que atribuíam ambas as exposições ao mundo que hoje denominamos subdesenvolvido no processo de construção da revolução socialista mundial, situação que contrasta com a importância atribuída por Marx e Engels às lutas dos povos chineses e indianos contra o colonialismo como fatores de aceleração da revolução europeia, quando, no entanto, a exploração do mundo atrasado tinha como ponta de lança o capital comercial. 
Até aqui esta rápida visão de algumas das ideias dominantes dentro do campo marxista na época em que fará sua aparição $A$ acumulação de capital, de Rosa Luxemburgo, obra que vai representar a primeira aproximação a uma visão totalizante do sistema capitalista mundial, dentro da qual tanto o desenvolvimento dos países avançados dominantes como o processo de subdesenvolvimento dos países e zonas dependentes são vistas, pela primeira vez e de modo teoricamente coerente, como aspectos de um mesmo processo dentro do contraditório desenvolvimento histórico de tal sistema.

\section{IV - A Visão Totalizante de Rosa Luxemburgo}

\section{1 - Desenvolvimento e subdesenvolvimento no modelo de Rosa Luxemburgo}

No prólogo à primeira edição de A acumulação de capital (1912) sua autora nos explica a origem de tal obra. Trabalhava na redação de suas conferências sobre economia marxista na Escola de Quadros do Partido Social-Democrata Alemão que reuniria em sua Introdução à Economia Política (1972), quando percebeu que não poderia “expor com suficiente clareza o processo global de produção capitalista em seu aspecto concreto, nem seus limites históricos objetivos" (Luxemburgo, 1967, p.9). Aprofundando no assunto considerou "que não se tratava simplesmente de uma dificuldade de exposição, mas que esta envolvia um problema teoricamente relacionado com a doutrina do volume II de $O$ Capital de Marx e que além disso transcendia a prática da política imperialista atual e suas raízes econômicas" (Idem).

O problema teórico reside em ter chegado à conclusão de que os esquemas de reprodução de Marx, baseados no conhecido suposto de considerar uma sociedade em que operassem apenas duas classes sociais, capitalistas e operários, colocavam um problema não solucionado por seu autor, que era a venda (realização) daquela parte do produto que correspondia ao valor da mais-valia não consumida pelos capitalistas. Se os trabalhadores compram uma parte do produto igual ao valor total de seus salários e os capitalistas só consomem uma parte do valor da mais-valia. Para quem é vendido o produto que contém a parte remanescente não consumida da mais-valia? A venda desta parte do produto que corresponde precisamente à porção suscetível de ser acumulada (investimento), é um requisito fundamental do processo global de reprodução ampliada do capital, de modo que se ela não se realiza, tal processo seria bloqueado. 
Por outra parte, o progresso técnico implícito no desenvolvimento capitalista implica numa tendência ao aumento da composição orgânica do capital que faria cada vez maior a diferença entre o produto criado e a capacidade de compra do mesmo pelos capitalistas e operários.

Depois desta constatação, que Goldmann (1969, s/p.) considera como "a maior descoberta teórica no domínio da crítica da economia política desde O Capital", Rosa Luxemburgo termina por encontrar a falha no esquema de Marx na suposição de considerar que nele participavam só duas classes sociais, capitalistas e operários, suposição que a seu juízo é irreal, porque corresponde apenas:

a tendência histórica objetiva do movimento da acumulação e seu resultado teórico final (...) não é mais que a expressão teórica daquele momento em que a dominação capitalista alcançou seu último limite (...) [Ao contrário, na realidade] o capitalismo está circunscrito, mesmo em sua plena maturidade, à existência coetânea de estratos e sociedades não capitalistas (Luxemburgo, 1969, p.322-329).

É precisamente nestes estratos e sociedades não capitalistas onde se realiza essa parte do valor do produto que não tem compradores no modelo de duas classes sociais de Marx. Dessa maneira, Rosa Luxemburgo encontra o argumento para proceder a abertura do modelo de reprodução do capital incluindo nele, não somente a acumulação da mais-valia extraída dos trabalhadores a serviço do capital, como também outras formas de sobre-produto extraídas dos trabalhadores dos setores e países não-capitalistas. Esses “dois aspectos da acumulação de capitais - sugerem - que se encontrem ligados organicamente pelas condições e reprodução do capital e só de ambos reunidos surge o curso histórico do capital" (Luxemburgo, 1969, p.351).

Mesmo reconhecendo a validade no plano teórico de muitas críticas feitas ao raciocínio da autora, sua exposição segue sendo para nós de importância fundamental. Com efeito, a abertura do modelo para incluir outras classes sociais, rompendo a homogeneidade do esquema original e introduzindo a verdadeira heterogeneidade socioeconômica do capitalismo como sistema mundial significa superar o que, de acordo com Lukács, não foi para Marx

Senão uma hipótese metodológica a partir da qual se deveria progredir para colocar o problema de modo mais amplo, para expor a questão enquanto totalidade da sociedade (Lukács, 1960, p.51-52).

Exposição que se sintetiza na consideração de que só a partir de ambos os aspectos da acumulação surge o curso histórico do capital. Saímos assim do restritivo marco teóricoeconômico do modo de produção capitalista puro ( $O$ Capital) e adentramos uma nova 
totalidade que abrange todas as manifestações da vida social e toda a riqueza da história: a formação econômico-social capitalista concebida em escala mundial.

Dentro desta formulação os países "não-capitalistas" que foram penetrados pela expansão do capitalismo em todos os cantos da terra, encontram pela primeira vez um lugar permanente dentro da história moderna da cultura ocidental. Não só por terem servido como fontes de acumulação originária do capitalismo, nem de que suas distintas zonas tenham desempenhado em distintos momentos uma importância intermitente nos assuntos mundiais, mas por ter constituído sempre um elemento vital e imprescindível do processo de formação e desenvolvimento do sistema capitalista mundial. Desta maneira, os quatro séculos de expansão da Europa sobre os outros continentes encontra sua primeira síntese histórica.

Faço aqui um breve resumo do raciocínio da autora:

1 - O capitalismo vem ao mundo num meio social não-capitalista e é dentro desse meio onde realiza seu desenvolvimento histórico. Nos países europeus ocidentais esse meio foi o feudalismo, que uma vez que entrou em processo de decomposição deu lugar a outro meio não-capitalista em que predominou a pequena produção mercantil (pequenos produtores na agricultura e artesanato em outros setores). No restante do mundo o capitalismo era cercado por "um conjunto de culturas não-europeias que oferecia toda escala de níveis de evolução, desde hordas comunistas primitivas de caçadores nômades até a produção camponesa e artesã mercantil" (Luxemburgo, 1960, p.283).

2 - Em meio a esse ambiente pré-capitalista o capitalismo atravessa três fases diferenciadas:

Primeiro, a luta do capital contra as organizações de econômica natural com a finalidade de: a) se apoderar de seus recursos naturais; b) liberar trabalhadores para logo obrigá-los a trabalhar para o capital; c) introduzir a economia mercantil, e; d) separar a agricultura da indústria. Este processo de decomposição das economias naturais não poderia ser realizado senão pela força, posto que "confiar aqui no processo secular de lenta decomposição interna destas formações equivaleria para o capital renunciar às forças produtivas daqueles territórios. Por isso que o capitalismo considera como uma questão vital a apropriação violenta dos meios de produção importantes dos países capitalistas" (Luxemburgo, 1960, p.285).

3 - A segunda fase é a luta do capital para destruir a economia mercantil simples que havia imposto como substitutivo à economia natural.

Revista de Estudos e Pesquisas sobre as Américas V.13 N.1 2019 ISSN: 1984-1639 
4 - A terceira fase é a fase imperialista da acumulação de capitais ou fase da concorrência mundial do capitalismo que "abarca a industrialização e emancipação capitalista dos antigos hinterlands do capital, nos quais realize sua mais-valia".

5 - Através do cumprimento destas três fases “o processo de acumulação tende a substituir em todas as partes a economia natural pela economia mercantil simples e estas pelas formas capitalistas, até fazer com que a produção capitalista domine absolutamente como forma de produção única de todos os países e ramos", embora indicando que tal homogeneização da economia mundial ao redor das formas capitalistas de produção corresponda apenas "à tendência histórica objetiva do movimento da acumulação, a seu resultado teórico final" (Luxemburgo, 1960, p.322).

6 - Convém aprofundar sobre a significação desse processo de substituição progressiva da economia natural pela economia mercantil simples e desta pelas formas capitalistas de produção. Através desse processo, Rosa Luxemburgo sugere que o capital transforma essas formas pré-capitalistas de produção, as adapta progressivamente às suas necessidades, de modo que "quando se diz que o capitalismo vive de formações não-capitalistas, é preciso dizer que ele vive das ruínas dessas formações e necessita do ambiente não-capitalista para absorvê-lo. Considerada historicamente, a acumulação de capital é um processo de mudança de formas verificada entre a forma de produção capitalista e as pré-capitalistas. Sem isso não se pode verificar a acumulação de capital, mas considerado neste aspecto a acumulação se efetiva destroçando-as e assimilando-as. Assim, portanto, nem a acumulação de capital pode se realizar sem as formações não-capitalistas nem aquelas podem sequer se manter. A acumulação só pode se dar graças a constante destruição preventiva daquelas" (Luxemburgo, 1960, p.322).

Existem aí duas abordagens básicas da autora sobre o que hoje se denomina como subdesenvolvimento, abordagens que apresentam como veremos em seguida, uma surpreendente coincidência com alguns dos mais importantes desenvolvimentos contemporâneos sobre a questão.

\section{2 - Uma comparação com as teorias modernas do subdesenvolvimento}

Como é conhecido, tanto o próprio conceito de subdesenvolvimento como os esforços em formular teorias que o expliquem, nascem depois da Segunda Guerra Mundial como parte das implicações da chamada "Guerra Fria". Foi precisamente dentro de tal contexto, 
coincidente com o desmoronamento dos velhos impérios coloniais, com a revolução das expectativas crescentes no seio do Terceiro Mundo e com a crescente atratividade que o exemplo do rápido desenvolvimento da União Soviética exercia sobre tais países, que os círculos acadêmicos da Europa e dos Estados Unidos descobriram, repentinamente, seu interesse pelo desenvolvimento do mundo subdesenvolvido e a necessidades de promover propostas de políticas econômicas dentro do marco capitalistas para fazer frente ao efeito demonstração que exercia o campo socialista.

Inicialmente este interesse foi traduzido na formulação de planos concretos que partiam do pressuposto de considerar o subdesenvolvimento como uma etapa pré-capitalista o desenvolvimento, cujos sintomas fundamentais eram um conjunto de carências fatoriais (baixa disponibilidade de capital, baixo nível de formação da força de trabalho, deficiências na dotação de recursos naturais, condições negativas impostas pelo meio geográfico etc.).

Muito rapidamente veio a percepção de que tal análise era, pelo menos, incompleta, pois várias tentativas de desenvolvimento baseadas em tais pressupostos foram incapazes de produzir os resultados esperados. Surgiram, assim, as propostas "estruturalistas" que viam nas diferenças institucionais e estruturais a razão do fracasso das tentativas de "modernização" da economia e entram na moda, no plano da política econômica, os programas reformistas concebidos para mudar essas instituições e estruturas retardatárias, como condição prévia ao processo de desenvolvimento que teria como meta a formação de economias capitalistas, baseadas nos padrões dos Estados Unidos e Europa Ocidental.

Pioneira deste enfoque, tanto desde o ponto de vista de sua construção teórica como da implementação de políticas desenvolvidas foi a Comissão Econômica para a América Latina (CEPAL). Mais de uma década de esforços estéreis nesse sentido vieram a pôr em evidência a incapacidade das políticas econômicas que surgiam do enfoque estruturalista, o que levou muitos de seus formuladores iniciais à revisão de seus postulados teóricos ${ }^{18}$. É então, em meados da década dos sessenta, quando vem a se descobrir que tanto as primeiras formulações baseadas nas carências de fatores (teorias fatoriais) como as formulações estruturalistas, que ao considerar o subdesenvolvimento como etapa a partir da qual deveria se dar el salto ao capitalismo, deixavam de lado o problema das interconexões históricas entre o desenvolvimento capitalista dos chamados países "centrais" e o subdesenvolvimento da "periferia".

\footnotetext{
${ }^{18}$ Refiro-me em especial aos trabalhos de Raúl Prebisch e Oswaldo Sunkel posteriores a 1967.
} 
Mesmo autores como Prébisch, Myrdal, Nurkse, Singer e outros que haviam enfatizado a influência das desigualdades na distribuição dos frutos do comércio internacional, o fizeram sem aprofundar na essência desses resultados, vendo-os com causas que mantinham a condição de subdesenvolvimento não como resultante lógica de um sistema mundial regido por leis que determinavam, ao mesmo tempo o desenvolvimento do centro e o subdesenvolvimento da periferia. Esta nova abordagem, que aparece pela primeira vez na literatura sobre o subdesenvolvimento na Economia Política do Crescimento de Paul Baran (1956), foi o ponto de partida de uma nova visão do problema que considera o subdesenvolvimento como aspecto complementar do desenvolvimento dos centros dominantes dentro do processo de formação histórica do sistema capitalista mundial. Daí parte a obra de André Gunder Frank, Fernando Henrique Cardoso, Enzo Faletto, Alonso Aguilar, Hector Silva Michelena, Theotonio Dos Santos, Anibal Quijano, Samir Amin, Mohammed Dowidar e todo o conjunto de autores latino-americanos e de outras latitudes que representam hoje o mais avançado campo de estudos sobre o subdesenvolvimento.

Fizemos esse breve recorrido da evolução das teorias do subdesenvolvimento para deixar em evidência como duas décadas de discussão teórica vieram ao final constatar o que Rosa Luxemburgo havia formulado sem igual clareza meio século antes, quer dizer, a unidade dialética entre acumulação de capitais no centro e a desacumulação e subdesenvolvimento na periferia. Seria, obviamente, absurdo pretender que Rosa Luxemburgo tenha nos deixado uma teoria acabada do subdesenvolvimento, porque esse não era e nem poderia ser seu objetivo. $\mathrm{O}$ que sim nos deixou, apesar das falhas teóricas que escreveram seus numerosos críticos, foi uma teoria do sistema capitalista mundial como totalidade, dentro do qual encontram lugar importante e as bases para uma explicação de si mesmos do que agora denominamos países subdesenvolvidos.

\section{3 - Rosa Luxemburgo e Lenin}

A concepção do sistema capitalista mundial como uma totalidade que abarca tanto aos países desenvolvidos como aos subdesenvolvidos é uma ideia que estaria também implícita no conceito de imperialismo e, em especial, na abordagem que Lenin (1972) fez da temática em Imperialismo, fase superior do capitalismo (1916). No entanto, o que neste aspecto diferencia de Rosa Luxemburgo, tanto de Marx como de Lenin, é que nossa autora dá absoluta continuidade histórica a tal totalidade e à necessidade de relações entre suas partes 
constitutivas. Com efeito, já vimos como o modelo teórico de Marx só demanda dos países não-capitalistas para explicar a acumulação originária na fase da gênese do capitalismo; por sua parte, no desenvolvimento de Lenin a importância do mundo "colonial, semicolonial e dependente" para o funcionamento pleno do capitalismo é uma característica de sua "fase superior", imperialista, não das anteriores ${ }^{19}$. Portanto, a base histórica das modernas teorias do subdesenvolvimento está, precisamente, nessa continuidade da exploração dos países atrasados pelo capitalismo desde seu primeiro contato com eles, tal como estabelecido na exposição de Rosa Luxemburgo.

Como consequência do antes exposto, o imperialismo, segundo ela não poderia ser definido só com base em sua necessidade de exploração dos países atrasados, processo que ela demonstra ter sido permanente, mas com base na forma concreta como se realiza a exploração: exportação de capitais, investimentos diretos, controle das fontes mundiais de matérias-primas pelos grandes consórcios monopolistas etc., aspectos estes nos quais sua exposição foi pouco precisa e nos quais Lenin, ao contrário, deixou uma exposição muito mais rica, mesmo quando, é justo reconhecê-lo, também insuficiente.

\section{4 - A natureza do comércio exterior}

Outro aspecto do raciocínio de Rosa Luxemburgo que conserva ainda hoje um caráter inovador e sugestivo é a concepção do comércio exterior que ela desenvolve em seu modelo de sistema capitalista mundial: Mercado exterior, para o capital, é a zona social não-capitalista que absorve seus produtos e lhe fornece elementos de produção e operários (Luxemburgo, 1967, p.281).

Consideramos que em tal concepção possam encontrar-se as bases para uma formulação da exploração capitalista dos países subdesenvolvidos, não com base da exploração de umas nações por outras, mas sim com base na exploração tanto da classe operária como das classes e camadas não-capitalistas pela burguesia, o que recoloca o problema das contradições dentro do sistema não só em termos de contradições entre "nações ricas e nações proletárias", mas também em termos da luta de classes em nível da totalidade, aspecto sobre o que se realizam hoje importantes discussões na América Latina.

\footnotetext{
${ }^{19}$ Esta é a ideia sugerida por algumas passagens do Capítulo VI de O Imperialismo, nas quais Lenin após destacar que foi após 1880 que tem início o grande auge das conquistas coloniais parece estar de acordo que antes de tal ano, "os dirigentes burgueses desse país (Inglaterra) eram adversários da política colonial" (Lenin, 1972, p.98-99).
}

Revista de Estudos e Pesquisas sobre as Américas V.13 N.1 2019 ISSN: 1984-1639 


\section{As críticas a A acumulação de Capital}

Desde sua aparição A acumulação de capital foi objeto de um ataque concentrado no qual participaram todas as tendências surgidas do processo de decomposição ideológica operada no seio da II Internacional depois da morte de Friedrich Engels. Tanto Kautsky, patriarca do "marxismo ortodoxo" da época, como Otto Bauer, representante do "austromarxismo" como Bernstein, teórico do "revisionismo" coincidiram em tratar de rebater as teses fundamentais da autora com base em argumentações nas quais aparecem, pela primeira vez com toda a clareza, as ideias que iam nutrir a corrente reformista que terminaria por dominar e aniquilar o movimento revolucionário em todo o centro da Europa. Em suas famosas "Anti-críticas"20 Rosa enfrentou com singular lucidez a este tipo de ataques, demonstrando o fundo oportunista de seus argumentos, de forma tal que a história lhe deu plenamente razão.

Infelizmente, sua obra também recebeu os ataques de Lenin por razões que podem ser facilmente compreendidas dentro do quadro das lutas ideológicas entre os revolucionários da época, ${ }^{21}$ razões que explicam também o caráter unilateral de tal crítica; que só viu erros nas proposições da autora, talvez porque não tenha tido tempo de ponderar seus importantes acertos, ou porque isso não convinha nos termos concretos das lutas políticas do momento. ${ }^{22}$ O fato em si é que o rechaço de Lenin, cuja influencia sobre o desenvolvimento do pensamento marxista seria dominante até nossos dias, condenaram por muito tempo a obra completa de Rosa Luxemburgo ao esquecimento.

Ainda hoje, quando o movimento de resgate do seu pensamento para a história do marxismo tomou um enorme vigor, considero que seguem predominando posições preconcebidas e argumentações aceitas a priori para julgar sua obra, o que leva a realizar sua

\footnotetext{
${ }^{20}$ Este ensaio aparece em espanhol como apêndice da edição de $A$ acumulação aqui citada.

${ }^{21}$ Como bem assinalou Nettl, Lenin tinha lido A acumulação em $1913 \mathrm{em}$ um momento em que suas relações políticas com Rosa Luxemburgo eram ruins. ("Sobre el imperialismo", El Desafio de Rosa Luxemburgo, Edit. Brocero, Buenos Aires 1972, p. 133).

O artigo de Lenin "Sobre o direito das nações à autodeterminação" (Obras escogidas, Ediciones en Lenguas Extranjeras, Moscu, 1960,. pp. 645-705) oferece um bom exemplo da dureza, só justificada pelo calor das lutas do momento, com que Lenin tratou as posições da autora.

${ }^{22}$ No artigo "Notas de un publicista"(Obras Completas, tomo 33), publicado em 1922 quando já havia sido superada por muitos motivos as bases da disputa com Rosa, Lenin cunha a frase: "Apesar de todos os equívocos, Rosa Luxemburgo foi e seguirá sendo uma águia", que é o reconhecimento póstumo a sua condição revolucionária e de marxista integral.
} 
leitura e discussão como uma espécie de busca por méritos e erros para então passar ao balanço de tais aspectos positivos e negativos.

Li de forma bastante detida muitos dos ensaios que críticos sobre $A$ acumulação de capital, e devo confessar que ficam muitas dúvidas, não só em relação a algumas das falhas teóricas que lhe atribuem, senão, ainda mais, no que diz respeito a validade de uma crítica que, em uns casos, fundamenta a refutação teórica em exposições que não são mais do que hipóteses e são apresentadas como teorias comprovadas ${ }^{23}$, ou que usam geralmente como argumento a incapacidade da autora para prever desenvolvimentos que agora aparecer muito lógicos e normais dentro do capitalismo contemporâneo, ou o descumprimento de suas supostas previsões sobre o futuro do sistema ${ }^{24}$.

Do mesmo modo que Marx, Rosa Luxemburgo constrói um modelo abstrato. Só que, enquanto no primeiro o capitalismo basta a si mesmo, no segundo requer de um meio não capitalista para subsistir. Como marxista, ela sustentou a validade do modelo essencial de $O$ capital no que concerne à descrição do modo de produção capitalista em sua versão pura. Mas ao tratar de lhe conferir aplicação histórica se vê diante da necessidade de ampliá-lo para dar lugar ao fato, absolutamente inquestionável, de que na realidade o capitalismo sempre precisou de setores ou países não capitalistas para resolver a problemática da acumulação do capital.

A todos os argumentos "teóricos" destinados a demonstrar que o capitalismo pode funcionar sem comércio exterior com outros meios não capitalistas pode-se opor uma afirmação historicamente irrebatível: até agora, o capitalismo nunca funcionou desta maneira. Mais ainda, o surgimento, desenvolvimento e crescente ampliação do campo socialista impedem que essa "situação teórica" possa ter lugar no campo da realidade.

Tanto do ponto de vista da concepção teórica que tenho do imperialismo, como da análise empírica de sua atual situação contemporânea, sou dos convencidos de que a liberação dos países subdesenvolvidos, a implantação neles do socialismo e sua consequente saída do sistema capitalista mundial, significam o fim do imperialismo, o que constitui outra maneira

\footnotetext{
${ }^{23}$ A crítica de Toro Toloza ("La acumulación de capital segundo Rosa Luxemburgo", Revista de Economic y Administración, Concepción, Chile 1971-72, N 19 y 20) é um exemplo neste sentido. Aceita-se ali como válido a priori, o esquema marxista de reprodução ao nível de abstração que o expôs Marx e dali se passa a criticar à autora por seu esquecimento (?) de "que em todo o corpo teórico está o essencial de um problema e que para aplicar essas categorias a um problema concreto se requerem alguns passos prévios e imprescindíveis", o que significaria deixar de lado todo o laborioso raciocínio da autora. Igual crítica merecem outros autores, cuja inclusão aumentaria demais esta nota.

${ }^{24}$ Neste tipo de crítica incluo Jacques Vallar ("La teoría del imperialismo de Rosa Luxemburg", en Teoria marxista del Imperialismo, Cuadenos Pasado y Presente, Córdoba, Argentina, 1969, p. 65).
}

Revista de Estudos e Pesquisas sobre as Américas V.13 N.1 2019 ISSN: 1984-1639 
de demonstrar que, ao menos na sua fase atual, o capitalismo requer, para poder subsistir sem que se detenha no processo de acumulação, de suas relações com o mundo subdesenvolvido. Daí que com todo o respeito que possam merecer as mencionadas argumentações teóricas sobre a possível autossuficiência do capitalismo, anteponho sobre elas os fatos da história.

Uma palavra final no que tange a criticada "conclusão catastrofista" sobre o futuro do capitalismo e sobre o que alguns de seus críticos qualificam de incapacidade para prever alguns dos desenvolvimentos que operaram no capitalismo contemporâneo.

Começarei por expressar que a mencionada "conclusão catastrofista" de Rosa Luxemburgo não expressa em si mesma nenhuma previsão concreta. Ela aponta somente que, com base em sua tese, converter ao capitalismo o último pedaço da terra, "o que não é mais do que uma construção teórica" ${ }^{25}$, se criariam as bases para a morte do sistema por incapacidade para cumprir as condições da acumulação. Dita afirmação tem um sentido tendencial, como por exemplo, a tese da queda da taxa de lucro de Marx. O fato de que nenhuma de ambas as situações tenham chegado a se apresentar não demonstra de modo algum a incorreção da exposição. Geralmente se argumenta, ao se referir à citada tese de Marx, que a mesma era válida dentro do quadro do capitalismo oitocentista que ele havia estudado. Uma argumentação similar, pode se aplicar à tese de Rosa Luxemburgo. Sua conclusão surge de um modelo que tem como um de seus principais supostos o caráter mundial total do sistema capitalista, o que significaria que com o advento da revolução socialista de outubro começam a desaparecer os supostos fundamentais de seu modelo, situação que se fará mais patente mais adiante sob o impacto de dois acontecimentos decisivos, a crise dos anos trinta e a segunda guerra mundial.

A crise dos anos 1930 marcou o fim do otimismo capitalista com respeito ao automatismo do sistema. Desaparece a confiança na capacidade do mercado para se autorregular e servir de bússola orientadora do crescimento e se cria o marco propício à chamada revolução teórica de Keynes, que faria da política do gasto público a válvula reguladora das inconsequências do mercado. Em outro aspecto, a crise serviu também para que fossem promovidas novas políticas no campo do comércio internacional com os países atrasados. É a época dos tratados de "reciprocidade comercial" destinados a impedir a industrialização de tais países, política que, por certo, colocava em evidência a necessidade de

\footnotetext{
${ }^{25}$ Assinalei este parágrafo da autora, porque nele se expressa a própria negação do conceito de "catastrofista". Muito mais "catastrofista" em termos concretos e não teóricos foi Engels em suas muitas opiniões sobre a conquista da China pelo capitalismo (ver nota 10).
}

Revista de Estudos e Pesquisas sobre as Américas V.13 N.1 2019 ISSN: 1984-1639 
impedir seu desenvolvimento capitalista, tal como se os países dominantes aceitassem a tese de Rosa Luxemburgo sobre a necessidade do capitalismo ter uma periferia não capitalista.

Por sua vez, a Segunda Guerra Mundial foi a prova definitiva da vitalidade do socialismo que emerge dela fortalecido e conformando um novo e poderoso sistema mundial em aberta contradição com o capitalismo, o qual se vê obrigado a realizar importantes mudanças para poder fazer frente ao desafio do novo poder em expansão. Uma dessas mudanças foi a necessidade de aceitar a industrialização da periferia, ainda que tomando os devidos cuidados para fazer dela uma industrialização limitada se possível ao setor leve e dominada do centro através de investimentos de capital e do controle tecnológico. O resultado em tal sentido foi promover naqueles países um capitalismo subdesenvolvido e dependente que segue desempenhando em relação ao capitalismo dos centros desenvolvidos dominantes um papel similar ao que desempenhavam as economias não capitalistas no modelo de $A$ acumulação de capital.

Faltaria pesquisar se a tese da conveniência mutua do incremento do comércio capitalista-socialista, sustentada pela URSS, não cria as condições de uma saída ao problema da realização da mais-valia capitalista por meio do enorme mercado dos países socialistas ${ }^{26}$. Se assim fosse, haveria um novo argumento a favor da tese de Rosa Luxemburgo sobre a necessidade para o capitalismo de setores e países não capitalistas para realizar a mais-valia. Ao final que as relações comerciais entre a URSS e os Estados Unidos sejam "mutuamente vantajosas",27, como sustenta Brezhnev, é outra questão que nos leva, certamente, a um novo problema teórico: o de se tal equilíbrio de resultados no intercâmbio entre os países imperialistas e os socialistas pode ser explicado pela teoria marxista ou se estamos frente a um renascimento da teoria dos vantagens comparativas de David Ricardo. Mas ainda aceitando este equilíbrio nos resultados haveria também que se perguntar: o fato de que esse intercâmbio seja favorável a ambos os países significa também que é favorável aos países subdesenvolvidos?

A questão concreta é que estamos frente a uma situação mundial completamente diferente da vivida por Marx, Lenin ou Rosa Luxemburgo. Pretender aplicar mecanicamente

\footnotetext{
26 “Apenas em um ano de comércio entre a URSS e os Estados Unidos, devido às medidas tomadas por ambos os países aumentou três vezes e as partes têm a intenção de fazer chegar a soma total do intercâmbio de mercadorias até os 2 ou 3 bilhões de dólares nos próximos três anos" (Un viraje Radical, editorial do jornal soviético Noticias de Moscú, junho de 1973, $\mathrm{n}^{\circ} 26$ (p.572)). De outro lado Brezhnev se referiu à necessidade de que os EUA e a URSS enfoquem no problema de seu intercâmbio comercial "de maneira ampla, em grande escala, tendo em conta uma perspectiva de largo prazo, para uns 20 anos" (Una visita en aras de la paz universal, Ibid.).

${ }^{27}$ A frase é do discurso de Brezhnev em sua reunião "com os grandes industriais norte-americanos" no último 22 de junho (Notícias de Moscú, 1973).
}

Revista de Estudos e Pesquisas sobre as Américas V.13 N.1 2019 ISSN: 1984-1639 
as conclusões que eles visualizaram na sua época histórica seria a negação do marxismo, o que não significa que na metodologia de análise que eles elaboraram não estejam elementos essenciais para uma visão cabal da problemática do mundo contemporâneo. Isso foi o que cada um deles fez para sua época e é o que nos corresponde fazer para a nossa.

\section{Referências}

BARAN, Paul. Economía política del crecimiento. México: Fondo de Cultura Económica, 1956.

BENSAID, Daniel y NAIR, Alan. “El problema de la organización”. In: LENIN y LUXEMBURGO. Partisans, Paris, 1969.

BOERSNER, Demetrio. The bolshevik and the colonial cuestion. París: Librarie E. Droz, 1957.

CÓRDOVA, Armando. "Fundamentación histórica del concepto de heterogeneidad estructural”. Revista “S”, n³, julio-agosto, 1972.

GOLDMANN, Lucien. "Recherches Dialectiques”. In: ARAY, E. Materiales para el estúdio de la acumulación y el imperialismo, tomo III. Caracas: S/E, 1969.

MARX, Karl, ENGELS, Friederich. Materiales para la historia de América Latina. Córdoba: Cuadernos Pasado y Presente, 1972.

MARX, Karl, ENGELS, Friederich. Sobre el Colonialismo. Córdoba: Cuadernos Pasado y Presente, 1973.

MARX, Karl. El Capital, tomo I. México: Fondo de Cultura Económica, 1946. El Capital, tomo II. México: Fondo de Cultura Económica, 1946a. El Capital, tomo III. México: Fondo de Cultura Económica, 1946b. . Sur les societes précapitalistes. París: Editions Sociales, 1970.

Noticias de Moscú, junho de 1973, no 26.

LENIN, Vladmir. Imperialismo, fase superior del capitalismo. Pekín: Edicciones en Lengua Estranjeras, 1972.

LUKÁCS, Georg. Historia et conscience de classe. París: Les Editions de Minuit, 1960.

LUXEMBURGO, Rosa. La acumulación de Capital. México: Editorial Grijalbo, 1967. Introducción a la economía política. Córdoba: Cuadernos Pasado y Presente, 1972.

SCORON, Pedro. "Introducción a recopilación”. In: MARX, Karl, ENGELS, Friederich. Materiales para la historia de América Latina. Córdoba: Cuadernos Pasado y Presente, 1972. 